\title{
Em busca do futuro perdido: Ernst Bloch, a história e a subterrânea "tradição da esperança"
}

\author{
In search of the lost future: Ernst Bloch, history and the subterranean \\ "tradition of hope"
}

\author{
Danilo Araujo Marques \\ danilomarques.his@gmail.com \\ Doutorando em História \\ Universidade Federal de Minas Gerais \\ Rua deputado Salim Nacur, 173, Bloco 3, apto. 605, Santa Amélia \\ 31555-190 - Belo Horizonte - MG \\ Brasil
}

\begin{abstract}
Resumo
Mais conhecido na história do pensamento ocidental como "filósofo da esperança", Ernst Bloch (1885-1977) parece ainda não ter sido suficientemente lido pelos historiadores. A partir de um breve percurso sobre a vida e a produção intelectual desse pensador, com este artigo - orientado pelo olhar do historiador -, visa-se abrir perspectivas para um estudo mais acurado a respeito daquilo que nos é indicado por sua concepção de história. Anima-nos a hipótese de que o retorno a Bloch e a reelaboração de suas ideias neste início de século talvez possam nos oferecer a possibilidade de uma alternativa teórica para o momento histórico de crise em que vivemos marcado por uma historicidade premida e perdida entre um passado que já não é e um futuro [porvir] que parece longe de se cumprir.
\end{abstract}

\section{Palavras-chave}

Filosofia da História; Temporalidade; Tradição.

\begin{abstract}
Known in the western thought's history as a "philosopher of hope," Ernst Bloch (1885-1977) still seems to be underestimated among historians. From brief remarks on the life and intellectual production of this thinker, this article aims to open perspectives in terms of a more accurate study on his understanding of history. This attempt is performed regarding the hypothesis that a return to Bloch and a reassessment of his ideas in the beginning of this century may perhaps offer us the possibility of a theoretical alternative to the historical moment of crisis in which we live - marked by an urged and lost historicity between a past that no longer exists and a future far from becoming true.
\end{abstract}

Keywords

Philosophy of history; Temporality; Tradition.

Recebido em: 11/6/2017

Aprovado em: 19/12/2017 
[...] em uma velha sociedade em declínio, como o Ocidente atual, surge uma certa intenção parcial e efêmera no sentido apenas descendente [do futuro]. Então, para aqueles que não conseguem achar uma saída para a decadência, o medo se antepõe e se contrapõe à esperança. O medo se apresenta como máscara subjetivista e o niilismo, como máscara objetivista do fenômeno da crise (BLOCH 2005, p. 14-15).

Estas palavras, que bem poderiam ter sido ditas ontem, foram escritas pelo filósofo alemão Ernst Bloch há pouco mais de 60 anos no prefácio de sua obra mais conhecida, O princípio esperança. É óbvio que o momento histórico era outro: passados quase dez anos desde o fim da Segunda Grande Guerra, a chamada "nova ordem mundial" já tivera tempo suficiente para se consolidar nos termos bipolares - e, não raro, esquizofrênicos - da Guerra Fria. Mas nem por isso deixa de impressionar a atualidade do diálogo travado por Bloch com "o tempo que Ihe foi dado na Terra", para usar a bela expressão de Hannah Arendt (1987, p. 9).

Sendo também um homem que viveu em "tempos sombrios", a identidade intelectual de Bloch foi forjada na primeira metade do século XX - "com suas catástrofes políticas, seus desastres morais e seu surpreendente desenvolvimento das artes e ciências" (ARENDT 1987, p. 9). ${ }^{1}$ Não obstante a turbulência de quaisquer épocas que sejam, Arendt nos ensina que "mesmo no mais sombrio dos tempos temos o direito de esperar alguma iluminação [...], que alguns homens e mulheres, na sua vida e obra, farão brilhar" (ARENDT 1987, p. 9). É, pois, a partir dessa lição que um motivo - com forte tom de problemática suscita a produção deste artigo: tendo em vista o chamado atual "regime de historicidade", diagnosticado como de "expectativas decrescentes" e crise dos mecanismos de abordagem do passado, trata-se de voltar à vida e obra de Ernst Bloch com os olhos de historiador a fim de rastrear na interpretação crítica do presente que lhe foi dado viver os traços de uma original filosofia da história (BLOCH 1998; GUMBRECHT 2012; HARTOG 2013; ARANTES 2014).

\section{Os primeiros traços de uma outra compreensão da história}

Nascido em 1885, Bloch passou para a história do pensamento ocidental como um dos mais conhecidos intérpretes contemporâneos do futuro entendido como porvir. Na qualidade de um legítimo intelectual público, o chamado "filósofo da esperança" produziu escritos em conexão direta com as questões mais urgentes de seu tempo. Essa ética de trabalho - mantida ao longo de seus 92 anos - começou a ser cultivada ainda na juventude, desde que Bloch deixou a Universidade de Berlim e os colóquios do professor Georg Simmel, em 1912, e passou a frequentar os encontros semanais do chamado "Círculo Weber de Heidelberg", a convite de um jovem amigo filósofo chamado György Lukács.

\footnotetext{
${ }_{1}^{1}$ Para ressaltar o elo de contemporaneidade que reúne os personagens biografados por Hannah Arendt sob o "guarda-chuva" de um mesmo tempo histórico - os tempos sombrios -, vale notar que Ernst Bloch também partilhou "a época em que decorreram suas vidas" (ARENDT 1987, p. 7). Acontece que, contrariando o critério pelo qual a autora justifica a seleção que fez dos nomes - eles "nem se conheciam" -, Bloch serviu como uma espécie de fio que costurou o hiato de relação entre alguns dos nomes biografados por Arendt, ao manter contato direto com Karl Jaspers e Walter Benjamin, por exemplo - ainda que o intercâmbio com este último, ao longo das décadas de 1920 e 1930, tenha sido estritamente oral, conforme relatado por Bloch em uma carta a Rolf Tiedemann, conhecido editor das obras de Benjamin (ZIMMER 2015, p. 115).
} 
A despeito das diferentes visões de mundo de seus membros, o grupo recebido aos domingos por Max Weber conservava, de acordo com Michael Löwy, "uma potente corrente anticapitalista romântica" (LÖWY 1979, p. 29). ${ }^{2}$ Foi por meio desses encontros que o "jovem filósofo judeu" --caracterizado, ainda nas palavras de Mariane Weber, por uma "enorme autoconfiança" e por suas "especulações apocalípticas" - aproximou-se de nomes como Karl Jaspers e Werner Sombart e passou a integrar um pequeno núcleo intelectual de oposição ao Império Alemão, formado por pensadores que, além de debater temas caros à epistemologia das humanidades, defendiam um misto de liberalismo, democracia e socialismo inspirados pela experiência revolucionária liderada por Louis Blanc na França em 1848 (WEBER 1988, p. 468-469; LÖWY 1979, p. 46-48).

Ao longo da turbulenta década de 1910, Ernst Bloch passou a preparar as notas daquele que seria seu primeiro livro, O espírito da utopia (1918), publicado em um momento de aguda crise política na Alemanha. Enquanto o país chegava exaurido ao fim da Primeira Grande Guerra - com cerca de 1 milhão e 800 mil mortos e 4 milhões de feridos -, a monarquia de Guilherme II dava os últimos suspiros diante da reverberação do espectro revolucionário nas manifestações da Liga Espartaquista de Rosa Luxemburgo e Karl Liebknecht, bem como da posterior proclamação social-democrata da República de Weimar (GALLO 2000; HARMAN 2008; GAY 1978).

Em meio a esse turbilhão de eventos, Bloch - que tinha visto com bons olhos a deposição do czar Nicolau II e a organização dos sovietes na Rússia, 104 mas desconfiava do centralismo bolchevique - tomava partido de uma leitura histórico-materialista sui generis do presente alemão, atentando, de um lado, para a derrota da Revolução Socialista de 1918 e o avanço do conservadorismo no Partido da Social-Democracia (SPD), e, por outro, o recrudescimento do militarismo e da suscetibilidade autoritária de milícias como as Freikorps integradas por veteranos da Primeira Guerra Mundial inconformados com a derrota da Alemanha e com o retorno à vida civil (JURADO 2001). "A guerra acabou", dizia ele no prefácio da segunda edição de 1923, "a revolução começou, e, com ela, as portas foram abertas. Mas, é preciso admitir, logo elas foram novamente fechadas. O aproveitador esforçou-se, conseguiu se instalar e, com ele, toda a antiga ordem está de volta" (BLOCH 1977, p. 9). Na medida em que se dedicava à tarefa de "estender sobre nossas cabeças não um céu indefinidamente em fuga, mas [...] um céu fundamentalmente real, utopicamente acessível", em seu primeiro livro, Bloch já abria caminhos para tópicas que seriam aprimoradas ao longo de toda sua obra ${ }^{3}$ (BLOCH 1977, p. 217-218).

\footnotetext{
2 Numa entrevista concedida em março de 1974 ao próprio Michael Löwy, Ernst Bloch parece contradizer essa leitura. Interrogado sobre a possibilidade de se afirmar "certa tendência anticapitalista" entre os integrantes do círculo Max Weber de Heidelberg, o filósofo alemão é taxativo: "Não é preciso exagerar [...] não se tratava exatamente de revolucionários. E o próprio Max Weber estava também bastante afastado da revolução" (LÖWY 1974 , p. 35; 1979, p. 282). "Éramos muito poucos", foi a resposta dada por Bloch quando Löwy insistiu na existência de uma "ala esquerda, antimilitarista" no círculo de Heidelberg. Para mais informações sobre a relação de Bloch com o círculo Max Weber de Heidelberg, cf. Karádi (1989, p. 499-514) e Boldyrev (2014, p. 7-38).

3 Este é o caso, por exemplo, da categoria existencial do "ainda-não-consciente", este lugar do "instante vivido" em que, na contramão do não-mais-consciente freudiano, "o iminente invade o presente" (BLOCH 1977 , p. 234). Como veremos adiante, na década de 1950, essa ideia foi capital para a formulação de uma ontologia do "princípio esperança" (BLOCH 2005).
} 
É dessa forma que se tem um dos primeiros registros de sua concepção de história. ${ }^{4}$ Ao criticar, por um lado, a falta de horizontes proporcionada pela fé em uma razão histórica, e, por outro, a "explicação de tudo" fornecida pelos savants e suas "mentirosas superestruturas", ${ }^{5}$ Bloch tratava de marcar a fronteira entre duas diferentes formas de abordagem da experiência passada dos feitos humanos (BLOCH 1977, p. 205). Para ele,

Se o passado é reconhecido como [...] mundo que não é mais consciente, como mundo independente do sujeito que sente e entende, ele é objeto da psicanálise [...]. Só a filosofia da história, rendendo ao passado o seu movimento, excedendo-o utopicamente, oferece novamente ao tempo, a essa forma intuitiva, a essa esfera onde opera a vitalidade ativa, seu lugar central (BLOCH 1977, p. 242-243).

Partindo, portanto, da intuição de que, longe de ser um conteúdo da realidade fechado e acabado em si mesmo, o passado está entremeado de latências não realizadas [ainda-não-conscientes], sendo, por isso mesmo, atravessado por um movimento que repercute no presente imediato do "instante vivido" - apreendido pela denominada "Filosofia da História" -, Bloch chama a atenção para o fator de articulação temporal que, entre outras coisas, parece possibilitar, inclusive, ao homem pensar em termos históricos, isto é, exercer sua consciência (espiritualidade) histórica. Isso porque

Não seria [...] mesmo pensável compreender épocas passadas [...], se não houvesse na história a intervenção alternada de duas espiritualidades diferentes, uma espécie de mudança de pólos, que nos faz hoje compreender a Grécia e a Renascença como a obra de pais afastados, e os Primitivos, o Egito, o gótico e sobretudo o barroco - interrompido unicamente por inaptidão - como a obra de nossos irmãos, sim, de nosso Eu mais próprio (BLOCH 1977, p. 319-320).

\footnotetext{
${ }^{4}$ Vale lembrar que dez anos antes da publicação de $O$ espírito da utopia, em julho de 1908, Ernst Bloch havia defendido uma tese de doutorado na Universidade de Wüzburg, intitulada "Rickert e o problema da moderna teoria do conhecimento", na qual criticava as teses da filosofia da história da escola neokantiana a partir de uma leitura hegeliana da teoria de Rickert - que relaciona o problema do conhecimento do mundo objetivo dos fato históricos com a capacidade cognitiva individual que capta esses mesmos fatos. Além de uma visão que polemiza tanto com o logicismo abstrato, quanto com o empiriociticismo positivista na abordagem da história, neste escrito, já aparecem - ainda que de maneira não sistemática - alguns conceitos e categorias que se tornarão elementos-chave na arquitetura de seu pensamento, tais como "esperança", "reino utópico" e "potência histórica" (cf. MÜNSTER 1997, p. 46-51).

${ }^{5}$ As duas frentes da crítica de Bloch tinham um único destino: o "esquematismo positivista" da explicação do processo histórico fornecida por aquela matriz do pensamento marxista legitimada desde a formação da Segunda Internacional em 1889. "É assim que a humanidade declina, no seu conjunto, privada de caminho, de objetivo além do cotidiano. Ela perde o que faz o ser verdadeiramente humano [...] e, por fim, todo impulso nobre e toda grande potência atomizam-se, diante do olhar savant, detalhes falsos, desencantados, todas as florações tornam-se retoques ou mentirosas superestruturas" (BLOCH 1977, p. 205). Foi por esse mesmo caminho que, em seu segundo livro, Bloch lançou uma ácida crítica à miopia do economicismo marxista frente a outros aspectos da realidade. "Assim representada, não basta uma pura reflexão econômica para, sozinha, explicar as condições e causas da erupção de um acontecimento histórico [...], bem como, pois, uma tal análise seria capaz de dissolver, de destruir o conteúdo profundo desta história humana [...]. O próprio Marx dá seu devido valor às exaltações místicas, pelo menos no começo de cada Revolução [...] o próprio Marx, que arrancara, de modo positivista, o Comunismo do domínio da Teologia, para lançá-lo ao da Economia, pura e simplesmente $[\ldots]$, reconhece pelo menos a realidade de impulso nas 'necromancias da História Mundial'. [...] As inclinações, os sonhos, as mais puras e mais sérias emoções, os entusiasmos conscientes do seu objetivo, não se alimentam apenas da necessidade mais perceptível e da ideologia nunca totalmente vazia" (BLOCH 1973, p. 48-49).
} 


\section{Por uma "História no seu sentido fecundo"}

O que parecia apenas o esboço de uma ideia sobre a história ganhou forma e conteúdo três anos depois com a publicação do segundo livro de Bloch, Thomas Münzer: o teólogo da revolução (1921). Engajar-se no passado como um conjunto de resquícios de um "momento atual" que invade o presente de modo que os outros se transformem, os mortos retornem e seu novo gesto reviva em nós: eis o sentido que Bloch atribuía à leitura de seu trabalho sobre o teólogo, reformador anabatista e líder das revoltas camponesas na Alemanha do século XVI, Thomas Münzer. ${ }^{6}$ Foi com esse trabalho que Bloch - de volta à Alemanha depois de passar dois anos na Suíça (1917-1919) fugindo do alistamento militar, publicando artigos sob diferentes pseudônimos no jornal Freie Zeitung e estudando as obras de Karl Marx e Friedrich Engels pretendeu inserir-se na tradição marxista de pensamento e abraçou de vez a causa política do comunismo, ainda que não tivesse aderido a nenhum partido e possuísse sérias reservas ao modo como Lenin - denominado por ele como "czar vermelho" - tratava os opositores da "ditadura do proletariado" na Rússia (MÜNSTER 2001, p. 118-128).

Apresentando a aplicação mais bem-acabada de uma percepção ética da História que rastreia no passado a existência de futuros possíveis e retoma, no presente, a longa - "meio esquecida, apenas em parte consciente" - "tradição da esperança", Bloch parte do pressuposto de que a vida dos homens "está sempre em processo e, em consequência, não fica fechada nos limites de seu tempo ou da História em geral, exercendo sua influência, enquanto sinal de testemunho, num campo meta-histórico" (BLOCH 1973, p. 207 e 6). É nesse sentido que "Münzer é, antes de tudo, História no seu sentido fecundo; seu presente e seu passado merecem a lembrança, lá permanece ele para comprometernos, entusiasmar-nos, para apoiar, sempre mais amplamente, nosso desígnio" (BLOCH 1973, p. 1, grifos meus).

Para Bloch, o estatuto epistemológico da História não estaria, portanto, restrito à estéril recordação daquele etos antiquado criticado por Friedrich Nietzsche em sua Segunda consideração intempestiva (NIETZSCHE 2003). Aliada às "categorias axiológicas da eficácia", a característica transformadora da historiografia derivaria mesmo do dom de possuir a potência da "mais autêntica 'reedição'" de maneira que, sob sua autoridade, os "mortos retornam, como num novo gesto, assim em significativo contexto, portador de novas descobertas" (BLOCH 1973, p. 7). Muito mais que ser um mero artifício narrativo

\footnotetext{
${ }^{6}$ Não era a primeira vez que alguém se interessava pela biografia de Thomas Münzer. Outros estudos sobre o radicalismo de sua teologia e atuação nas Guerras Camponesas do século XVI já haviam sido realizados no século XIX por nomes como Friedrich Engels (1946) e Karl Kautsky (2011). Não obstante, logo de início Bloch deixa claro o perfil que pretende acentuar em seu biografado: que "só se considere a vida ativa de Münzer, isto é, Münzer enquanto político, e não a sua Teologia. Com efeito, mesmo neste ativo teólogo da Revolução, os dois aspectos, ação e fim longínquo, ideologia e ideia puramente religiosa, tão intimamente se confundem que [...] vêm-se-lhe confundir, quase imediatamente, o ódio dos senhores, o ódio do clero, a reforma da Igreja e o êxtase do advento" (BLOCH 1973, p. 13). Bloch procura se diferenciar daqueles outros autores na medida em que, do ponto de vista de uma heterodoxa leitura marxista, enxerga na trajetória política do religioso Münzer não o germe, mas o próprio agente histórico de uma tradição emancipatória: "Münzer e os batistas em geral representam, aliás do ponto de vista político, por completo, a esquerda, o novo radical princípio intransigente da Reforma: um impulso na direção do desprendimento do termo e da liberdade, na acentuação da absoluta auto-responsabilidade ética-religiosa" (BLOCH 1973, p. 97-98).
} 
de acontecimentos que foram e não são mais, a História disporia do vivo poder da re-atualização de instantes vividos em meio à "riqueza incompleta do passado", revisitados a partir do critério básico de continuidade da subterrânea e inacabada "tradição da esperança".7 Trata-se, enfim, de liberar no presente as forças do passado, fazer brilhar agora "a centelha que não há mais de demorarse em parte alguma", entendendo que "a liberdade dos filhos de Deus é [...] a substância da História, para iluminar-nos e fortalecer-nos, no rebelde in Christo, Thomas Münzer!" (BLOCH 1973, p. 8).

Ao se concentrar na noção de devir histórico como um processo ao mesmo tempo inacabado e subterrâneo, para Ernst Bloch, a História se dedicaria à cata do omitido, do esquecido nas "ruínas e esferas culturais arrasadas deste mundo" (BLOCH 1973, p. 207). Dessa maneira, ao mesmo tempo em que o autor privilegia a ideia de rastro (Spuren), ${ }^{8}$ problematiza aquela figura linearteleológica tão cara às modernas Filosofias da História - inclusive da tradição marxista - e propõe uma reavaliação do conceito de tempo histórico.

São esses os pressupostos que balizam a hipótese da "não simultaneidade dos tempos" (Ungleichzeitigkeit), ${ }^{9}$ apresentada sob o postulado segundo o qual

Nem todos estão presentes no mesmo tempo presente. Aparentemente estão porque é possível vê-los aqui e agora. Mas não é só por isso que uns e outros vivem no mesmo tempo. Pelo contrário, alguns possuem um passado que se intromete. [...] Tempos mais antigos que os atuais continuam a viver nas camadas mais antigas [do presente] (BLOCH 1978, p. 95).

Essa premissa foi desenvolvida no núcleo teórico do livro Herança deste tempo, redigido ao longo dos anos 1920, mas publicado apenas no final de outubro de 1934, nas difíceis condições de exílio na Suíça (MACHADO 2016, p. 49). Escrito no sentido de uma autoanálise crítica do fracasso das esquerdas e

\footnotetext{
7 À primeira vista, os trabalhos de Bloch parecem ter exercido grande influência sobre os escritos de Walter Benjamin a respeito da História. Para além da relação "quase simbiótica" entre esses dois pensadores - de acordo com um termo empregado pelo próprio Bloch -, dois traços comuns aos seus escritos chamam logo a atenção: por um lado, a proposta do artifício de atualização (Aktualität) do passado; por outro, a defesa de uma História dos oprimidos (ZIMMER 2015, p. 115). Se ambos os temas aparecem como fragmentos ao longo da produção benjaminiana - e ganham relevo nas Teses sobre o conceito de História, em 1940 -, o mesmo já ocorre no livro de Bloch sobre Thomas Münzer, publicado quase vinte anos antes, em 1921: seja com a ideia da "mais autêntica reedição" da "tradição da esperança" - algo parecido com aquilo que Benjamin trata como "o dom [que tem o historiador] de despertar no passado as centelhas da esperança"; ou mesmo com a noção de que "os próprios vencidos, em Thomas Münzer e em tudo que lhe diz respeito, pertencem já à Filosofia da História: [...], com as meditações de um outro mundo, na sua base" (BLOCH 1973, p. 8). Para outras possíveis mediações entre as elaborações teóricas de Ernst Bloch e Walter Benjamin, cf. Zimmer (2015) e Machado (2016, p. 97-107).

8 Spuren é o título do terceiro livro de Bloch, publicado em 1930. Nele, o autor compõe um ajuntamento de notas, verbetes e pequenos textos - aparentemente banais - sob o entendimento de que rastros são "como estacas plantadas na água, areia ou neve para sondar e sinalizar o percurso do rebanho humano conduzido na direção da História" (BLOCH 1968, p. 104), Cf. (MÜNSTER 1997, p. 203-215). É nessa medida que, conforme reproduziu o próprio Walter Benjamin em sua obra inacabada, a "formulação de Ernst Bloch sobre o trabalho das Passagens" pode ser aplicada à sua conduta de um leitor de vestígios: "A história mostra seu distintivo da Scotland Yard'. Foi no contexto de uma conversa", diz Benjamin sobre Bloch, "em que explicava como esse trabalho - comparável ao método de fissão atômica - liberta forças gigantescas da história, que ficam presas no 'Era uma vez' da narrativa histórica clássica" (BENJAMIN 2006, N3, 4, p. 505). Para um estudo da concepção de traço na compreensão que Ernst Bloch tem da ideia de História, cf. Lyotard (1976).

${ }^{9}$ A categoria Ungleichzeitigkeit é traduzida aqui como "não simultaneidade", em vez de reproduzir a opção da tradução francesa por "não contemporaneidade". Isto porque o termo "não simultaneidade" parece aproximarse mais da ideia de algo que não ocorre ao mesmo tempo, expressa no vocábulo utilizado por Bloch no original em alemão. Além do mais, Bloch não faz uso dos termos zeitgenössisch ou Zeitgenossenschaft, que, neste caso, seriam muito mais apropriados às noções de "contemporâneo" e "contemporaneidade".
} 
da ascensão do Partido Nacional-Socialista dos Trabalhadores Alemães (NSDAP) - que, nas suas palavras, "levou de roldão o escroque chamado Adolf Hitler" -, Bloch sentenciava logo nas primeiras linhas do prefácio: "A situação é lastimável, ou abjeta, o caminho de saída, tortuoso" (BLOCH 1978, p. 7).

Mais uma vez a Alemanha atravessava um profundo momento de crise política. Acontece que, dessa vez, quem dava o último suspiro era a República de Weimar. Se, em 1918, a sensação que parecia latente em meio àquele turbilhão de eventos era a da transição de um regime autocrático para uma república socialdemocrata, a partir de 1933, a impressão que se impunha era a do "nascimento de uma era negra" (GAY 1978, p. 184). Diante desse novo contexto, Bloch tratava de sublinhar o leitmotiv político de seu trabalho: "A época se putrefaz e ao mesmo tempo grita como uma mulher prestes a dar à luz. [...] É tempo de arrancar as armas das mãos da reação" (BLOCH 1978, p. 7-8).

E o objetivo de tornar pública a teoria da "não simultaneidade dos tempos" não parecia ser outro senão esse. ${ }^{10}$ Isso porque, se, por um lado, Bloch tratava da relação que existe entre as diferentes temporalidades que subjazem às formas de oposição ao moderno racionalismo instrumental - tradições, mitos, símbolos e alegorias adversos à "máquina de morte do capitalismo" -; por outro, ele pretendia alertar o leitor para o sucesso com que os nazistas - em detrimento das esquerdas alemãs - souberam capitalizar esse "elemento da vida" em benefício próprio (BLOCH 1978, p. 94).

Para Bloch, o tempo histórico é um composto dialético de temporalidades 108 vividas que não estão orientadas na mesma direção. Desse modo, um mesmo presente pode acolher temporalidades que nada possuem de simultâneas, mas que, nem por isso, deixam de orientar a ação humana. Como já havia apontado em seu livro sobre Münzer, Bloch lança mão do conceito de herança para mostrar essa copresença entre o passado dito "irracional" da tradição e o porvir da confiante - "embora destroçada" - razão moderna. ${ }^{11}$ Para ele, é a herança que converte e media a coexistência de temporalidades tão distintas em um mesmo presente, além de tornar possível a integração, a comunicação e a reinvenção contínua de tradições no seio de uma sociedade.

Mas, como dito acima, havia ainda outro fator - de ordem ético-política - que Bloch pretendia esclarecer com sua teoria da "não simultaneidade dos tempos". Trata-se dos "elementos subversivos e utópicos, a matéria reprimida do que não ocorreu", a esperança não contemporânea que permanece incubada na tradição que o presente herda do passado (BLOCH 1978, p. 20). Negligenciado pela compreensão etapista de análises demasiado economicistas e orientadas apenas para o telos da revolução, mas mobilizado com maestria pela retórica demagógica do Partido Nazista, o excedente emancipatório daquela "pulsão

\footnotetext{
${ }^{10}$ Vale notar que o livro Herança deste tempo não se resume à exposição da teoria da "não simultaneidade dos tempos". Outras questões de ordem estético-filosófica - como a polêmica sobre o lugar histórico das vanguardas artísticas e apropriação metodológica da noção de montagem - também são abordadas por Bloch neste trabalho (cf. MACHADO 2016, p. 49-87).

${ }^{11}$ A partir dessa postura um tanto "herética" de um marxista que se volta para o conteúdo do passado e sai em defesa de um retorno - ainda que de um ponto de vista ativo - à tradição, fica evidente a influência do Romantismo no pensamento blochiano. A respeito do "socialismo místico e libertário" de Ernst Bloch, Cf. "Romantismo e utopia: o sonho acordado de Ernst Bloch" (LÖWY 1995, p. 278-304).
} 
anticapitalista" era justamente a arma que Bloch tanto queria arrancar das mãos da reação (BLOCH 1978, p. 95). "As velhas formas", dizia ele,

colaboram em parte para a novidade, quando elas são bem dispostas. 0 inimigo viu melhor [...] que essas formas são extremamente eficazes.

É tempo de recuperar algumas velhas coisas, a urgência da hora nos ordena. A indolente arrogância com que um Kautsky zombava dos "heróis" ou das "pequenas amostras da mística apocalíptica" e se contentava em ridicularizá-las está ultrapassada, tanto na teoria quanto na prática (BLOCH 1978, p. 133).

Ao mesmo tempo em que traçava um quadro crítico da prepotente negligência com que as esquerdas trataram o tema da tradição - a "subalimentação da imaginação socialista", que selou o fracasso de seu projeto político diante do ardiloso programa proposto pela extrema direita na Alemanha -, Bloch também acusava o conceito linear e o automatismo do progresso como pilares teóricos da concepção de história do marxismo vulgar. Antes de referendar qualquer imagem de um tempo homogêneo e vazio, ou de um passado fechado e encerrado na sucessão dos acontecimentos, o tempo histórico para Bloch estaria permeado de potências não realizadas. Trata-se mesmo de uma dialética multifacetada de tempos e espaços que não está mais interessada no movimento linear da história, mas na mediação de processos heterogêneos que atuam no presente; ${ }^{12}$ algo como uma justaposição dos conteúdos históricos, contrária à representação segundo a qual é melhor ou "mais evoluído" aquilo que é ou está posterior na sequência dos eventos (ZIMMER 2015, p. 118).

\section{Consciência antecipadora e princípio esperança: peças chave para uma nova ideia de história}

Por questões de segurança, Bloch encontrava-se exilado em Zurique, na Suíça, desde que o Partido Nazista havia vencido as eleições para o Reichstag em março de 1933. Acontece que a tradicional neutralidade política relativa à recepção de imigrantes naquele país não era a mesma dos anos 1910. Além da forte onda de antissemitismo que se espraiava pela população, a polícia suíça estava empenhada na perseguição de militantes comunistas e potenciais "agentes do Komintern". Devido à visibilidade política provocada pela publicação de seu livro-manifesto contra o nazismo, Bloch - após uma curta passagem por Viena e Paris - decidiu se transferir, em 1935, para a capital da antiga Tchecoslováquia, acompanhado de sua companheira, a arquiteta comunista Karola Piotrowska. Mas, apesar da intensa atividade de oposição ao nazismo na revista tcheca Neue Weltbühne, a estadia em Praga foi breve: após a assinatura do Acordo de Munique, em setembro de 1938, a Tchecoslováquia foi incorporada ao Terceiro Reich. Sem a mínima condição de voltar para a Alemanha, o filósofo

\footnotetext{
12 Ao traçar um interessante paralelo entre a noção blochiana de tempo e as considerações topológicas feitas pelo matemático alemão e contemporâneo Bernhard Riemann a respeito do caráter orientável das superfícies, Jörg Zimmer vê no multiversum de conteúdos históricos adotado por Bloch em sua teoria da "não simultaneidade dos tempos" "um pressuposto teórico e metodológico imprescindível para o conceito de memória (Erinnerung) histórica" (ZIMMER 2015, p. 116).
} 
deixou a Europa de uma vez por todas e acompanhou o movimento de muitos outros intelectuais alemães de origem judia dessa mesma geração, ao buscar refúgio nos Estados Unidos da América.

Apesar de não ser fluente em inglês nem conseguir emprego ou espaço para publicar seus escritos, ao longo de 11 anos Bloch não se manteve isolado. Foi nesse período que se reaproximou de outros intelectuais alemães exilados naquele país - como Theodor Adorno, Max Horkheimer e Herbert Marcuse - e estabeleceu certa relação de diálogo com a principal proposta da Escola de Frankfurt: elaborar um modelo crítico de leitura do presente por via de uma renovação da teoria marxista, independente da compreensão regulamentada pela burocracia soviética (JAMESON 1997). Além disso, foi durante esses anos que concluiu os manuscritos de O princípio esperança e do livro Sujeito-objeto: considerações sobre Hegel, cuja primeira edição foi publicada em espanhol, no México, em 1949 (BLOCH 1983). Quatro anos após o fim da Segunda Grande Guerra, Bloch retornou ao território dividido da Alemanha. Estabeleceu-se na recém-proclamada República Democrática Alemã (RDA), onde, muito bemvindo, assumiu a direção do Instituto de Filosofia da Universidade Karl Marx em Leipzig e retomou o ritmo de suas publicações - começando pela edição alemã de Sujeito-objeto (1951) e o livro Avicena e a esquerda aristotélica (1952), mais uma iniciativa empenhada em resgatar tradições esquecidas (MÜNSTER 2001, p. 208-269).

Dois anos depois, em 1954, o conjunto da obra de Ernst Bloch - e, como 110 consequência, o que entendemos como sua concepção de história - ganhou mais um novo sentido com a publicação do primeiro volume de $O$ princípio esperança. Se até então, Bloch havia acenado para uma nova concepção do passado e do tempo histórico, com este trabalho ele passou a perseguir os rastros de um tema latente desde 1918, o da "consciência antecipadora", e assumiu a tarefa de propor uma hermenêutica de sua expressão mais positiva: a esperança, ${ }^{13}$ esse "lugar do mundo tão habitado quanto as terras mais cultivadas e tão inexplorado quanto a Antártida" (BLOCH 2005, p. 16).

Desde a pulsão mais básica da fome - que pavimenta o curso para a

\footnotetext{
${ }_{13}$ Vale notar que o sentido do conceito "esperança" em Ernst Bloch não está ligado à recorrente noção de uma espera passiva, contemplativa, mas à concepção ativa de aspirar a uma promessa algo próximo da noção de Hatikvah na tradição judaica. A despeito das edições inglesa, espanhola, italiana e portuguesa utilizarem as palavras que remetem para a acepção vulgar do substantivo alemão - respectivamente hope, esperanza, speranza e esperança, talvez mesmo por falta de um termo mais apropriado - vale notar que a tradução francesa não faz uso do substantivo espoir, mas de espérance, que possui um significado muito mais relacionado ao sentido de um "bem que se espera receber em herança" (ESPÉRANCE 1968, p. 346). Logo no prefácio da edição alemã, o próprio Ernst Bloch deixa clara essa distinção entre a espera passiva (Erwartung) do "chegará aquilo que deve chegar" - o chamado "futuro inautêntico" - e o ato de espera (Hoffnung), a esperança como princípio da vida ativa, do "futuro autêntico": "O ato de espera não resigna: ele é apaixonado pelo êxito em lugar do fracasso. A espera, colocada acima do ato de temer, não é passiva como este, tampouco está trancafiada em um nada. [...] A vida de todos os seres humanos é perpassada por sonhos diurnos [...] Não no sentido do entendimento meramente contemplativo, que aceita as coisas como são e estão no momento, mas no da participação, que as aceita em seu movimento, portanto, também como podem ir melhor" (BLOCH 2005, p. 13-14).
} 
formação de "afetos expectantes" como a angústia ou a esperança - à capacidade imaginativa dos "sonhos diurnos" - função utópica que não permite a conformação "com o precário que aí está" -, para Bloch o que se dispõe no horizonte de todo ser é o sentido da possibilidade, o ato de intencionar a tendência na sua potencialidade (BLOCH 2005, p. 14). Dessa maneira, ele retoma a concepção de "tradição da esperança" e sugere como base para o conhecimento da consciência antecipatória a apreensão do "aindanão-consciente", a pré-consciência do que está por vir, que "comunica-se e interage com o que-ainda-não-veio-a-ser, mais especificamente com o que está surgindo na história do mundo" (BLOCH 2005, p. 23).

Para um melhor entendimento da concepção de "ainda-não-consciente", tomemos como exemplo a inflexão temporal da epistemologia psicanalítica. Em linhas gerais, do subconsciente de Gottfried Leibniz ao porão da consciência de Sigmund Freud e o inconsciente coletivo de Carl Jung, o presente é descrito e analisado apenas nos termos da incidência de um não-mais-consciente recalcado. A proposta de Bloch é justamente inverter o sentido desta "aurora para trás", tendo em vista que "em todo o presente, mesmo no que é lembrado, há um impulso e uma interrupção, uma incubação e uma antecipação do que ainda não veio a ser. E esse interrompido-irrompido não ocorre no porão da consciência, mas sim na sua linha de frente" (BLOCH 2005, p. 21-22). ${ }^{14}$

No entanto, não se trata de ajustar o sentido da história rumo a uma resplandecente imagem do que está por vir, uma meta para a humanidade ou mesmo um fim da história. Como já foi possível perceber, a aversão de Bloch à inexorabilidade da concepção linear do progresso histórico foi uma constante no conjunto de sua obra. A problemática que havia sido levantada em Herança deste tempo foi retomada em um tratado escrito em 1956, intitulado "Diferenciações no conceito de progresso". Neste texto, Bloch se opunha à noção redutora de história defendida pelo marxismo oficial da Internacional Comunista, ao alegar que, junto ao progresso, existe um desenvolvimento do passado que produz repercussões no presente. "Se não fosse assim", dizia ele, "não existiria nenhuma herança cultural capaz de seguir influenciando [...]. Esses grandes excedentes culturais do acontecido se encontram [...] eles mesmos envolvidos num progresso específico, com aspectos de seu conteúdo que vez por outra se tornam acessíveis" (BLOCH 1970, p. 122).

Em meio aos eventos que, nesse mesmo ano, derrubaram o governo de Imre Nagy sob o jugo repressivo das tropas do Exército Vermelho em Budapeste, Bloch endureceu ainda mais suas críticas aos ideólogos do Partido Comunista, alinhados às diretrizes stalinistas da União Soviética. Visto como um potencial oposicionista e um "perigo para a juventude", o Partido Socialista Unificado da Alemanha (SED) e a Stasi - polícia secreta da RDA - passaram a persegui-lo,

\footnotetext{
${ }^{14}$ Além de expressamente demarcar a fronteira entre seu projeto filosófico e aquele da psicanálise freudiana, Bloch deixa clara a distinção entre seu conceito de "ainda-não-consciente" (Noch-nicht-benwusstes) e o conceito de "pré-consciente" (Vorbewusstes). Isto ocorre na medida em que Bloch, em sua fenomenologia do "ainda-não-consciente", volta-se para a manifestação dos sonhos diurnos, enquanto Freud privilegia o fenômeno dos sonhos noturnos em sua Interpretação dos sonhos (FREUD 2001).
} 
sob a acusação de "atividades reformistas" (COMBE 1999, p. 63). A querela tornou-se pública em 1957, com a organização de uma conferência na cidade de Berlim intitulada "Bloch: revisionista do marxismo". Esta foi a deixa para que uma enxurrada de publicações começasse a atacar o filósofo e a denunciar a incompatibilidade de seus escritos com os preceitos da teoria marxista firmada pelo Komintern. Em 1958 - portanto, nove anos após ter sido recebido como uma espécie de "pensador oficial da RDA" -, Bloch foi proibido de dar aulas e aposentado compulsoriamente, ao mesmo tempo em que sua companheira Karola era expulsa do SED (MÜNSTER 2001, p. 234-271).

Foi dessa condição de isolamento político no centro da Alemanha socialista que, em 1959, publicou o terceiro e último volume de O princípio esperança. Se cinco anos antes, o pensador havia lançado sua tese sobre o sentido da consciência antecipadora e dos "sonhos diurnos" como complemento de sua leitura do passado, agora ele encaixava mais uma importante peça na estrutura de sua compreensão da história. Muito antes de se lançar para frente ou para trás na arquitetura do tempo, diz ele, a "vontade última é a de estar verdadeiramente no presente" (BLOCH 2005, p. 26). De um ponto de vista prático, voltar os olhos para aquilo que Bloch havia denominado em 1954 de "ainda-não-consciente" seria o mesmo que se referir a um carpe-diem. Não aquele habitual, dionisíaco e hedonista, que salta de um instante para o outro e não passa da superfície momentânea do gozo, mas um "carpe-diem autêntico", que "fareja o ar da manhã" e age "como decisão no instante exigido, como força para não desperdiçar a oportunidade oferecida 112 por ele" (BLOCH 2005, p. 288-290).

Dessa forma, em vez de avalizar, por um lado, um telos inexorável para a história ou, por outro, um futuro longínquo para a conquista da perfeição humana, o conceito blochiano inscreve no presente a perspectiva do novum e o dilata (BLOCH 1966). O "ainda-não" não é simplesmente a combinação entre o que existe agora e a projeção do que existirá no futuro, entre a realidade imediata e as pretendidas - ou passivamente esperadas - aspirações. Ele atravessa "diagonalmente o que já se tornou existente e vai além deste". (BLOCH 2005, p. 303-304). Se pensarmos em termos koselleckianos, ele é a tensão no presente entre a permanência do que já foi realizado - o "campo da experiência" - e a possibilidade do que ainda está se formando - o "horizonte de expectativas" (KOSELLECK 2008). ${ }^{15}$ É assim que Bloch reconhece esse explosivo momento da ação como o "impulsionador contínuo da história", dado que "cada instante, como não manifestado, situa-se no ano zero do início do mundo" (BLOCH 2005, p. 302-304, grifos do autor).

Ao ter notícias de que um muro estava sendo construído para segregar o "setor americano da cidade" de Berlim, em 1961, Bloch pediu asilo à República Federal da Alemanha (RFA) e instalou-se em Tubinga, onde retomou suas atividades acadêmicas e públicas como professor visitante. Nessa pequena cidade universitária, participou de campanhas contra a Guerra do Vietnã (1955-

\footnotetext{
${ }^{15}$ Acontece que Bloch não vê este instante apenas como um efêmero ponto de passagem entre aquelas duas categorias propostas por Reinhart Koselleck em sua leitura do moderno Sattelzeit (KOSELLECK 2008). Cercado por um conjunto muito maior de reminiscências do passado e possibilidades reais, para o autor, o presente imediato está em movimento e se amplia, conforme já havia sido apontado em Herança deste tempo (BLOCH 1978).
} 
1974), tornou-se um dos principais entusiastas das manifestações estudantis em 1968 e um ferrenho crítico do terrorismo como forma de ação praticada pelo grupo Baader-Meinhof - ala armada da esquerda alemã decorrente da radicalização dos movimentos estudantis. Lá permaneceu, ao lado de Karola Piotrowska, até sua morte em agosto de 1977 (MÜNSTER 2001, p. 271-322).

\section{Conclusão: repetir Bloch no século XXI}

Feito esse breve percurso, em parte biográfico-intelectual, em parte teórico, sobre a vida e a obra de Ernst Bloch, consideramos que, em um momento histórico crítico, diagnosticado como de "expectativas decrescentes" e marcado tanto pelo chamado "regime de historicidade presentista"16 quanto pela irrupção de uma "era da nostalgia", ${ }^{17}$ um possível caminho para nós, historiadores, seja justamente aquele indicado pelo pensador alemão: reelaborar o conceito de tradição e voltarse para o passado como "um tempo saturado de 'agoras'", nos quais, guardado o princípio da "não-simultaneidade", pulsam um sem-número de "promessas que ainda não se tornaram existentes" (HARTOG 2013; ARANTES 2014; LÖWY 2005, p. 119; BLOCH 2005, p. 325). Como aponta o historiador Russell Jacoby, vivemos em "uma época de emergências permanentes [...] mesmo assim, é possível argumentar em favor [...] de uma escrita da história sob o impulso não deste, mas de outro período" (JACOBY 2007, p. 9). É nessa medida que, hoje, nos parece enriquecedor o desenvolvimento de uma reflexão que pretenda rastrear os vestígios da ideia de história presente no pensamento de Ernst Bloch a partir da investigação do diálogo travado com seu próprio tempo.

Mas não se trata apenas de comentá-lo. Mais do que apresentar uma hermenêutica da obra blochiana tendo em vista o olhar do historiador, um "horizonte de expectativas" mais amplo coloca-se à nossa frente: voltar ao pensamento desse filósofo a partir do que nos indica sua própria noção de história. Ainda temos muito que aprender com Bloch neste início de século. A devida atualização de suas reflexões pode muito bem nos auxiliar na formulação de abordagens originais a respeito de nosso próprio presente - este mesmo em que "andamos sobre uma lâmina, [...] ainda e por pouco suspensos da queda fatal" (BLOCH 1973, p. 174). É desta maneira que a possiblidade de uma alternativa

\footnotetext{
${ }_{16}$ Para o historiador François Hartog, diferentemente do moderno "regime de historicidade futurista" - que, na tese de Reinhart Koselleck, orientava o curso da história somente para um "horizonte de expectativas" -, desde a Queda do Muro de Berlim, em 1989, "o [moderno] futurismo deteriorou-se sob o horizonte e o presentismo o substituiu. O presente [autocentrado e autorreferente] tornou-se o horizonte" (KOSELLECK 2008; HARTOG 2013, p. 148). Para outras leituras e desdobramentos dessa hipótese, Cf. A chegada do homem-presente (LAÏDI 2001), Gumbrecht (2012) e Arantes (2014).

17 Partindo do diagnóstico de Svetlana Boym de que o "século XX se iniciou com utopia e terminou em nostalgia", Zygmunt Bauman começou seu último livro fazendo referência ao "anjo da história" de Benjamin para sair em defesa do que chamou de "retrotopia" - ou, em termos blochianos, o resgate do excedente utópico que resta esquecido nas ruínas do passado (BOYM 2017, p. 153). Para o sociólogo polonês, "não é estranho que, havendo perdido ou dado as costas a toda visão de uma sociedade alternativa (melhor) e associando como consequência esse futuro, se não com algo 'pior que o presente', como 'mais do mesmo' [...] recorramos nostalgicamente ao momento de buscar ideias genuinamente significativas às grandes ideias enterradas (prematuramente?) do passado" (BAUMAN 2017, p. 126). Em tempos onde o traço de certa nostalgia - "restauradora", nos termos de Boym - aparece expresso em frases como "Bom mesmo era na ditadura" ou até mesmo no slogan da campanha que levou Donald Trump à presidência da nação mais poderosa do mundo - Make America great again -, talvez uma das questões de ordem ético-política mais urgentes para o campo da historiografia diga respeito ao alerta para escolhas que evitem as armadilhas na abordagem do passado e da tradição legada.
} 
nos é indicada: repetir Bloch. Não no sentido vulgar da importação mecânica e cega de seu arcabouço teórico e de suas inflexões ético-políticas. Repetir Bloch hoje significa, muito antes, revisitar o espectro de possibilidades aberto pelos seus escritos; repetir o seu gesto tendo em vista as novas circunstâncias históricas, na acepção mesma do latim re-petere - "pedir, interrogar, procurar novamente" (CUNHA 1986). Revisitar sua obra não apenas no campo do que efetivamente foi feito, mas daquilo que não Ihe foi possível fazer, do horizonte que se manteve inalcançável, inconcluso. Com isso, temos a chance de voltar à escuridão daquele "amontoado de ruínas do passado" de que fala Walter Benjamin para rastrear o que há de promessa, ainda-não, possíveis horizontes teóricos, centelhas que iluminem o tempo em que vivemos - tal como nos indica Hannah Arendt. Desse modo, não nos cabe apenas falar sobre Bloch, mas como sugerido pelo próprio pensador alemão em sua obra a respeito de Hegel - "para ele, com ele e inteiramente através dele" (BLOCH 1983, p. 3).

\section{Referências bibliográficas}

ARANTES, Paulo Eduardo. O novo tempo do mundo: e outros estudos sobre a era da emergência. São Paulo: Boitempo, 2014.

ARENDT, Hannah. Homens em tempos sombrios. Traduzido por Denise Bottmann. São Paulo: Companhia das Letras, 1987.

BAUMAN, Zygmunt. Retrotopía. Traducción de Albino Santos Mosquera. Barcelona: Paidós, 2017.

BENJAMIN, Walter. Passagens. Edição alemã de Rolf Tiedemann; organização da edição brasileira de Willi Bolle; tradução do francês de Cleonice Paes Barreto Mourão. Belo Horizonte: Ed. UFMG; São Paulo: Imprensa Oficial do Estado de São Paulo, 2006.

BLOCH, Ernst. O homem como possibilidade. Tradução de Emmanuel Carneiro Leão. Tempo Brasileiro, ano IV, n. 8, p. 15-28, 1966.

. Differenzierungen im Begriff Fortschritt. In: Gesamtausgabe: Tübinger Einleitung in die Philosophie. Frankfurt am Main: Suhrkamp, 1970. v. XIII.

Thomas Münzer: teólogo da revolução. Rio de Janeiro: Edições Tempo Brasileiro, 1973.

L'esprit de I'utopie. Traduit de I'allemand par Anne-Marie Lang et Catherine Piron-Audard. Paris: Gallimard, 1977.

Héritage de ce temps. Traduit de l'allemand par Jean Lacoste. Paris: Payot, 1978.

Sujeto-objeto: el pensamiento de Hegel. Traducción de Wenceslao Roces (edición original), José María Ripalda (capítulo VI), Guillermo Hirata y Justo Pérez del Coral (adiciones de 1951 y 1962). México: Fondo de Cultura Económica, 1983. 
Traces. Traduit de I'allemand par Hans Hildenbrand et Pierre Quillet. Paris: Gallimard, 1968.

O princípio esperança. Tradução de Nélio Schneider. Rio de Janeiro: EdUERJ; Contraponto, 2005. 3 v.

BOLDYREV, Ivan. Heidelberg's apostles: Bloch reading Lukács reading Bloch. In:

Ernst Bloch and his contemporaries. New York: Bloomsbury Academic, 2014.

BOYM, Svetlana. O mal-estar da nostalgia. História da historiografia, n. 23, p. 153-165, 2017.

COMBE, Sonia. Une société sous surveillance: les intellectuels et la Stasi. Paris: Albin Michel, 1999.

CUNHA, Antônio Geraldo da. Dicionário etimológico Nova Fronteira da língua portuguesa. 2. ed. rev. e acrescida de um suplemento. Rio de Janeiro: Nova Fronteira, 1986.

ESPÉRANCE. In: DUBOIS, Claude et al. Nouveau Petit Larousse. Paris: Librairie Larousse, 1968, p. 346.

FREUD, Sigmund. A interpretação dos sonhos. Tradução de Walderedo Ismael de Oliveira. Rio de Janeiro: Imago, 2001.

GALLO, Max. Une femme rebelle: vie et mort de Rosa Luxembourg. Paris: Éditions Fayard, 2000.

GAY, Peter. A cultura de Weimar. Tradução de Laura Lúcia da Costa Braga. Rio de Janeiro: Paz e Terra, 1978.

GUMBRECHT, Hans Ulrich. Graciosidade e estagnação: ensaios escolhidos. Tradução de Lúcia Villas Bôas, Markus Hediger. Rio de Janeiro: Contraponto; Ed. PUC-Rio, 2012.

HARMAN, Chris. The lost revolution: Germany 1918-1923. Chicago: Haymarket Book, 2008.

HARTOG, François. Regimes de historicidade: presentismo e experência do tempo. Tradução de Andréa Souza de Menezes, Bruna Beffart, Camila Rocha de Moraes. Belo Horizonte: Autêntica, 2013.

JACOBY, Russell. Imagem imperfeita: pensamento utópico para uma época antiutópica. Tradução de Carolina de Mello Bomfim de Araújo. Rio de Janeiro: Civilização Brasileira, 2007.

JURADO, Carlos Caballero. The German Freikorps: 1918-1923. Oxford: Osprey, 2001.

KOSELLECK, Reinhart. Futuro Passado: contribuição à semântica dos tempos históricos. Tradução de Wilma Patrícia Maas, Carlos Almeida Parreira. Rio de Janeiro: Contraponto; Ed. PUC-Rio, 2006. 
LAÏDI, Zaki. L'urgence ou la dévalorisation culturelle de l'avenir. Esprit, n. 240, p. 8-20, 1998.

. La tyrannie de I'urgence. Montreal: Fides, 1999.

A chegada do homem-presente: ou da nova condição do tempo. Tradução de Isabel Andrade. Lisboa: Instituto Piaget, 2001.

LÖWY, Michael. Interview with Ernst Bloch. New German Critique, n. 9, p. 3545, 1976.

Para uma sociologia dos intelectuais revolucionários. Tradução de Heloisa Helena A. Mello, Agostinho Ferreira Martins e Gildo Marçal Brandão. São Paulo: LECH Livraria Editora Ciências Humanas, 1979.

; SAYRE, Robert. Revolta e melancolia: o romantismo na contramão da modernidade. Tradução de Guilherme João de Freitas Teixeira. Petrópolis: Vozes, 1995.

Walter Benjamin: aviso de incêndio - uma leitura das teses "Sobre o conceito de história". Tradução de Wanda Nogueira Caldeira Brant, [tradução das teses] Jeanne Marie Gagnebin e Marcos Lutz Müller. São Paulo: Boitempo, 2005.

LYOTARD, Jean-François. Puissance des traces ou contribution de Bloch à une histoire païenne. In: RAULET, Gérard. Utopie-marxisme selon Ernst Bloch. Paris: Payot, 1976.

116 KARÁDI, Éva. Ernst Bloch and Georg Lukács in Max Weber's Heidelberg. In: MOMMSEM, Wolfgang J.; OSTERHAMMEL, Jürgen. Max Weber and his contemporaries. New York: Routledge, 2006.

MACHADO, Carlos Eduardo Jordão. Um capítulo da modernidade estética: debates sobre o expressionismo. São Paulo: Ed. Unesp, 2016.

MÜNSTER, Arno. Utopia, messianismo e apocalipse nas primeiras obras de Ernst Bloch. Tradução de Flávio Beno Siebeneichler. São Paulo: Editora da Universidade Estadual Paulista, 1997.

. L'utopie concrète d'Ernst Bloch: une biographie. Paris: Éditions Kimé, 2001.

NIETZSCHE, Friedrich. Segunda consideração intempestiva: da utilidade e desvantagem da história para a vida. Tradução de Marco Antônio Casanova. Rio de Janeiro: Relumé Dumará, 2003.

WEBER, Marianne. Max Weber: a biography. Translated and edited by Harry Zohn. New Brunswick: Transaction Books, 1988.

ZIMMER, Jörn. Progresso e recordação em Ernst Bloch e Walter Benjamin. In: MACHADO, Carlos Eduardo Jordão; MACHADO Jr., Rubens; VEDA, Miguel (Org.). Walter Benjamin: experiência histórica e imagens dialéticas. Tradução de Marlene Holzhausen, Carlos Eduardo J. Machado, Artur S. Bez, Fábio R. Uchôa e Rafael M. Zanatto. São Paulo: Ed. Unesp, 2015. 